\title{
Impact of Electronic Cigarettes on Various Organ Systems
}

\author{
Adam EM Eltorai, Ariel R Choi, and Ashley Szabo Eltorai

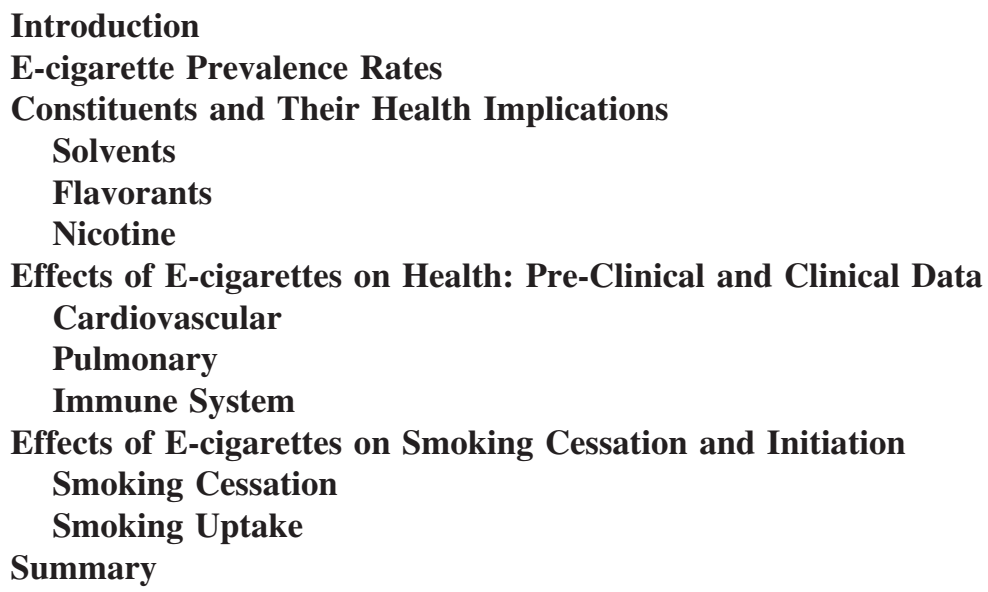

The electronic cigarette (e-cigarette) has been regarded by many as a healthier alternative to the combustible cigarette, yet there is a lack of consensus concerning the health consequences and the health benefits associated with e-cigarette use. We review the research on the effects of e-cigarettes on multiple physiological systems, examine the association between e-cigarette use and combustible cigarette uptake and cessation, and highlight research necessary to build consensus. Although the levels of known toxicants and carcinogens tend to be significantly lower in e-cigarettes than in combustible cigarette smoke, toxicants in e-cigarette e-liquid and those that form as part of the vaporization process may produce adverse health consequences in their own right. Acute effects have been noted in the pulmonary, cardiovascular, and immune systems, which highlight the need for research on long-term exposure. The specific chemical constituents and the levels of those constituents that pose harm remain largely uncharacterized. In addition, the efficacy of e-cigarettes for smoking cessation has yet to be established. As the e-cigarette has evolved rapidly, so has the methodology across studies, making cross-study comparisons more difficult to synthesize. The latest generation of e-cigarette devices deliver nicotine and toxicants at higher levels than earlier devices, especially in experienced users. E-cigarettes pose a risk for nicotine exposure, dependence, and combustible cigarette uptake. E-cigarettes and their delivered toxicants appear harmful to multiple organ systems, although the current body of evidence is limited, especially in terms of long-term effects. Further research is warranted with a focus on individual devices, e-liquid constituents, user characteristics, and patterns of use. Any potential benefit of e-cigarettes for smoking cessation must be weighed against the risks. Given the potential longer-term effects, efforts to prevent e-cigarette use in youth are critical. Key words: e-cigarette; electronic cigarette; smoking; vaping; cessation; health effects; addiction. [Respir Care 2019;64(3):328-336. (c) 2019 Daedalus Enterprises]

\section{Introduction}

The electronic cigarette (e-cigarette) was developed in China in 2003 as an alternative to the combustible cigarette, and it entered United States markets in 2006. ${ }^{1}$ The e-cigarette mimics combustible cigarette smoking by thermally vaporizing a liquid for inhalation that consists of solvents, flavorants, and nicotine. E-cigarette sales have continued to increase in the United States, ${ }^{2}$ with $6.7 \%$ of adults $^{3}$ and $11.3 \%$ of high school students ${ }^{4}$ reporting current e-cigarette use. Popularity has been fueled in part by perceptions among adults and youth that e-cigarettes are less harmful than combustible cigarettes. ${ }^{5,6}$ Indeed, the e-cigarette has gained widespread appeal for its supposed 


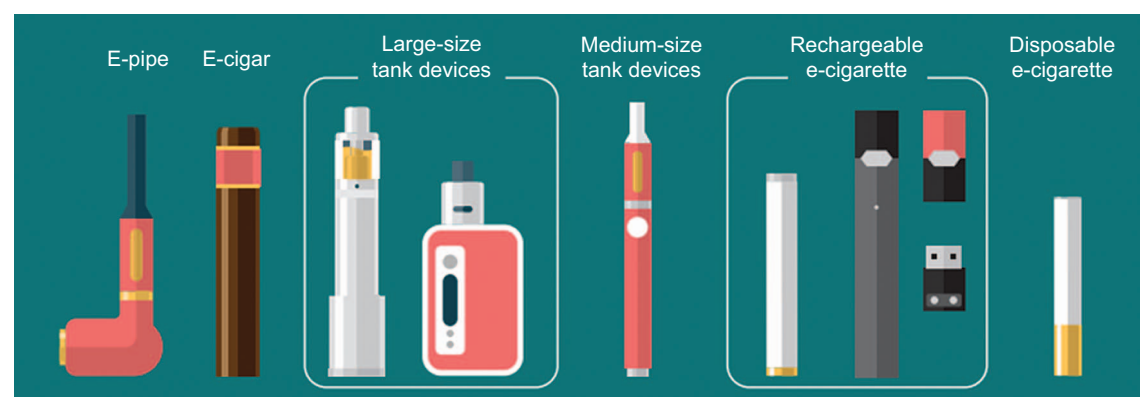

Fig. 1. Types of e-cigarettes. Courtesy of the Centers for Disease Control and Prevention.

safety and for its viability as a potential smoking cessation aid. $^{7}$

While research indicates that e-cigarettes deliver lower levels of known toxicants than combustible cigarettes, ${ }^{8}$ the unique (relative to combustible cigarettes) health risks associated with e-cigarette use are a subject of ongoing investigation. We review the pre-clinical and clinical data regarding the effects of e-cigarettes on major organ systems and highlight important gaps in clinical data. We also review the evidence for the efficacy of e-cigarettes in smoking cessation, as many smokers have failed to quit smoking with evidence-based therapies ${ }^{9}$ and are increasingly considering the e-cigarette as a smoking cessation aid. We conclude with a review of the health consequences of ecigarette use among adolescents, a population among which reduced perceptions of harm coupled with a variety of flavors especially enhance the appeal of e-cigarettes. ${ }^{10}$

To identify primary studies eligible for review, we queried the PubMed and Cochrane Library electronic databases in June 2017. Our search of the PubMed database was conducted using the command: "Electronic Cigarettes"[MeSH] AND "Health" [MeSH], yielding 85 results. To search the Cochrane Library, we applied the following search strategy: electronic cigarette (Title, Abstract, Key words) AND health (Title, Abstract, Key words). We subsequently limited our results to "Trials," the only nonreview option that yielded any results (51 results). All titles and corresponding abstracts were screened to identify eligible studies with full text availability. For additional primary studies and relevant literature reviews, we browsed the reference lists of eligible articles.

\section{E-cigarette Prevalence Rates}

The prevalence of e-cigarette use in the United States has risen dramatically. A survey of approximately 15,000

Drs AEM Eltorai and Choi are affiliated with the Warren Alpert Medical School of Brown University, Providence, Rhode Island. Dr AS Eltorai is affiliated with Yale University School of Medicine, New Haven, Connecticut. adults between 2010 and 2013 revealed a roughly 7-fold spike in ever e-cigarette use (from $1.8 \%$ to $13.0 \%$ ) and an even larger increase in current use from $0.3 \%$ to $6.8 \% .^{11}$ Current traditional combustible cigarette smokers had the highest rate of e-cigarette use $(64.7 \%)$, while one third of e-cigarette consumers were nonsmokers of traditional combustibles. A nationally-representative sample of 32,320 adults surveyed between 2013 and 2014 highlighted that adults continue to use e-cigarettes at these rates. ${ }^{3}$

E-cigarettes are the now the most commonly used tobacco product among youth in the United States. ${ }^{4}$ With an 8-fold increase in e-cigarette use since $2011,11.3 \%$ of high school students report currently using e-cigarettes, exceeding the prevalence of combustible cigarette smoking (8.0\%). About $4.3 \%$ of middle school students reported currently using ecigarettes in 2016, reflecting a 7-fold increase from $0.6 \%$ in 2011. While many youth who use e-cigarettes also use other tobacco products, a significant percentage of youth initiate e-cigarette use without previous tobacco use. ${ }^{12}$

\section{Constituents and Their Health Implications}

E-cigarettes have evolved rapidly, varying in appearance as well as features that determine the e-cigarette device's power (Fig. 1). Newer models typically employ a lithium-ion battery, which has been cited as the cause of a growing number of e-cigarette explosion injuries in recent years. ${ }^{13}$ Between 2009 and 2016, there were 195 reports of e-cigarette explosion injuries (including flame burns, chemical burns, and blast injuries) in the United States, 38 (29\%) of which were characterized as severe and required hospitalization; commonly injured body parts include the face, hands, thighs, and groin. ${ }^{14}$ In addition to the battery component, e-cigarettes generally include a heating element

Correspondence: Adam EM Eltorai PhD, Warren Alpert Medical School, Brown University, 70 Ship St., Providence, RI 02906. E-mail: adam_eltorai@brown.edu.

DOI: $10.4187 /$ respcare.06300 
and a container for e-liquid. The liquid that is vaporized for inhalation consists of one or two solvents (propylene glycol, vegetable glycerin), flavorants (fruit, dessert, mint, tobacco), and typically nicotine. ${ }^{1}$

\section{Solvents}

Propylene glycol has been associated with upper respiratory infection-like symptoms. ${ }^{15}$ It is formed by the hydration of propylene oxide, which is a probable human carcinogen. ${ }^{16,17}$ Vegetable glycerin exposure is associated with irritation of the eyes, lungs, and esophagus. ${ }^{18}$ Vaporization of the glycerol constituent forms the compound acrolein, which is a potent skin, eye, and nasal irritant as well as a potential carcinogen. ${ }^{19}$

The ratio of propylene glycol to vegetable glycerin in e-liquid may induce the formation of reactive oxygen species, which have been found in e-cigarette vapor. ${ }^{20}$ Reactive oxygen species have been linked to cardiovascular disease, neurodegenerative disorders, sensory deficits, and psychiatric disease. ${ }^{21} \mathrm{~A}$ recent study showed that a mixture of propylene glycol and vegetable glycerin produced more reactive oxygen species than either solvent alone. ${ }^{20}$ The e-liquid that most e-cigarette users report using is composed of propylene glycol and vegetable glycerin..$^{22}$ Ethanol also is frequently incorporated as a solvent, with a recent study showing that $71 \%$ (30 of 42) of e-liquid brands contained ethanol, ${ }^{23}$ which has been associated with reduced psychomotor functioning. ${ }^{24}$

In addition to glycols, toxicants formed during the vaporization of e-liquid include aldehydes, metals, volatile organic compounds, and polycyclic aromatic hydrocarbons. ${ }^{25}$ Exposure to volatile organic compounds, found in emissions from thousands of different products, can elicit health effects including eye and respiratory tract irritation, neurological impairment, and liver damage. ${ }^{26}$ Polycyclic aromatic hydrocarbons are a group of $>100$ compounds formed from incomplete burning of organic substances with demonstrated carcinogenic, respiratory, immunological, neurological, and reproductive effects. ${ }^{27}$ Moreover, studies of multiple e-cigarette brands have reported measurable amounts of various heavy metals (with carcinogenic, nephrotoxic, neurotoxic, and hematotoxic properties) in e-cigarette vapors and liquids; examples of these metals are silicon, lead, and nickel. ${ }^{28,29}$ Analyses of e-cigarette aerosols have indicated detectable air pollutant levels on the basis of markers like particulate matter mass concentration (eg, PM2.5) and particle number concentration. ${ }^{30,31}$ Other toxicants found in e-cigarette vapor include formalin, acetaldehyde, isoprene, acetic acid, 2-butanodione, acetone, and propanol. ${ }^{32}$ Some studies report that that the levels of e-cigarette toxicants do not present a health risk $^{28,33}$ or are lower than those present for combustible cigarettes, ${ }^{28}$ while other studies suggest that the levels are concerning. ${ }^{32,34}$

\section{Flavorants}

Still other toxicants found in e-cigarette vapor include flavoring compounds like diacetyl-like diacetin-is approved for flavoring but not inhalation. Diacetyl has been shown to reduce lung capacity as measured by $\mathrm{FEV}_{1} \cdot{ }^{35} \mathrm{An}$ alternative to diacetyl, 2,3-pentanedione, has been associated with airway fibrosis in rats. ${ }^{35}$ Due to limited research, the health effects brought about by inhalation of e-cigarette flavorings in humans are generally not well characterized. ${ }^{36}$ However, one recent study determined that diacetyl, pentanedione, and multiple other flavoring chemicals often found in e-cigarettes, including acetoin (butter), diacetyl, maltol (malt), and ortho-vanillin (vanilla), elicit a significant pro-inflammatory response in human lung epithelial cells and primary lung fibroblasts. ${ }^{37}$ Flavoring exposure has also been shown to significantly and rapidly (within $20 \mathrm{~min}$ ) decrease transepithelial resistance in human bronchial epithelial cells, suggesting epithelial barrier dysfunction and an impaired inflammatory response. ${ }^{37}$ Despite concerns about flavorant-induced respiratory toxicity (mainly pertaining to diacetyl and its substitutes, such as 2,3-pentanedione and 2,3-hexanedione), there is minimal regulation of these chemicals.

\section{Nicotine}

Commonly available e-cigarette liquids contain nicotine concentrations ranging from $0-36 \mathrm{mg} / \mathrm{mL}$. An initial study of 30 brands of e-cigarettes found that 30 puffs were required to deliver nicotine in an amount equivalent to that provided by a combustible cigarette, ${ }^{38}$ but subsequent research has shown that variables aside from stated liquid nicotine concentration can significantly influence nicotine yield. ${ }^{39}$ User characteristics (eg, puff duration, combustible cigarette smoker, experienced e-cigarette user) and ecigarette features (eg, device voltage, resistance) can determine whether a set quantity of e-cigarette puffs yield far more (or far less) nicotine relative to a single combustible cigarette. ${ }^{39}$

A recent study examined 16 long-time e-cigarette users who underwent multiple 10-puff vaping (exhale and inhale e-cigarette vapor) sessions with varying liquid nicotine concentrations $(0,8,18,36 \mathrm{mg} / \mathrm{mL})$ while keeping characteristics related to the e-cigarette device and e-liquid constant. ${ }^{40}$ Ten puffs at $36 \mathrm{mg} / \mathrm{mL}$ were sufficient to yield nicotine delivery that exceeded that of a typical combustible cigarette. With higher-wattage output to the atomizers, the newer devices deliver nicotine more efficiently, yielding 35-72\% greater plasma nicotine levels than firstgeneration devices. ${ }^{41}$ An additional concern is that nico- 
tine levels in e-liquid can deviate significantly from labeled amounts. ${ }^{38}$ This may increase overall nicotine exposure, including among adolescents, whose neurologic maturation is not yet complete, fostering nicotine dependence. $^{42}$

\section{Effects of E-cigarettes on Health: Pre-clinical and Clinical Data}

\section{Cardiovascular}

Animal studies have investigated the impact of e-cigarette vapor on cardiovascular health. Farsalinos et $\mathrm{al}^{43} \mathrm{ex}-$ amined the relationship between cardiac cytotoxicity and e-cigarette vapor by comparing various concentrations of cigarette smoke extract, e-cigarette vapor extract, and a base liquid sample (50\% glycerol and 50\% propylene glycol without nicotine or flavorings) on rat cardiac myoblasts. Two e-cigarette power voltages $(3.7 \mathrm{~V}$ and $4.5 \mathrm{~V})$ were also evaluated. Cigarette smoke extract was cytotoxic at all concentrations above $6.5 \%$, while the base extract was not cytotoxic at any of the concentrations. Vapor generated with higher power output resulted in greater cell death. Another study investigated the potential hazards of vaping on cardiac development, using in vitro human embryonic stem cell and in vivo zebrafish embryo models. ${ }^{44}$ Treatment of zebrafish with nicotine alone had minimal impact on cardiac differentiation, but treatment with either e-cigarette aerosol or cigarette smoke resulted in a greater incidence and severity of cardiac defects. Human embryonic stem cells exposed to e-cigarette extract showed significantly lower expression of several late-stage contractile proteins and transcription factors. Combustible cigarette smoke impairments were markedly more severe and diverse.

Several clinical studies have compared the cardiovascular effects of e-cigarette vaping to those of combustible cigarette smoking. One study examined the acute effects of both short-term cigarette smoking and vaping on left ventricular function. ${ }^{45}$ Heavy smokers $(n=36)$ and e-cigarette users who were former smokers $(n=40)$ had an echocardiogram before and after smoking 1 cigarette or vaping for $7 \mathrm{~min}$, respectively. Compared to the smoking group, the e-cigarette group showed no adverse effects on indices of left ventricular function. A more recent study ${ }^{46}$ examined circulating endothelial progenitor cells and microvesicles of endothelial origin at $1 \mathrm{~h}, 4 \mathrm{~h}$, and $24 \mathrm{~h}$ after exposure to e-cigarette vapor, looking for elevated levels of endothelial progenitor cells and microvesicles to indicate cardiovascular insult. Occasional smokers $(n=16)$ were randomized into 2 groups. One group was exposed to 10 puffs of e-cigarette vapor across $10 \mathrm{~min}$, and one group was not exposed to any vapor. ${ }^{46}$ The short-term vaping resulted in elevated levels of endothelial progenitor cells and microvesicles. Interestingly, this increase persisted for at least $4 \mathrm{~h}$ but returned to baseline by $24 \mathrm{~h}$. The results suggested that these effects were similar in magnitude to those observed after smoking a cigarette.

In a crossover study of 40 subjects ( 20 smokers, 20 nonsmokers), Carnevale et $\mathrm{al}^{47}$ investigated the vascular safety of e-cigarettes compared to that of combustible cigarettes, with respect to oxidative stress and endothelial dysfunction. All subjects smoked a combustible cigarette and, 1 week later, vaped an e-cigarette with the same nicotine content. Blood samples were drawn before and after smoking and vaping. The researchers found that both cigarette types were associated with increased oxidative stress (measured by soluble NOX2-derived peptide and 8-iso-prostaglandin F $2 \alpha$ ), impaired antioxidant defense (measured by reduced vitamin E), and dysfunctional endothelium (measured by reduced flow-mediated dilation and nitric oxide bioavailability). Relative to vaping, however, combustible smoking induced significantly greater changes in the levels of certain markers (soluble NOX2-derived peptide, 8 -iso-prostaglandin F2 $\alpha$, and nitric oxide bioavailability). Moreover, compared with non-smokers, smokers showed significantly higher baseline levels of these same markers. Taken together, these studies suggest that vaping may compromise cardiovascular health, at least acutely. Depending on the e-cigarette features, the effects may be less than or comparable to those of traditional cigarette smoking.

\section{Pulmonary}

The effects of e-cigarettes on pulmonary health have also been evaluated in multiple animal studies. McGrathMorrow et $\mathrm{al}^{48}$ exposed neonatal mice daily to e-cigarette vapor either with or without nicotine for the first $10 \mathrm{~d}$ of life. Mice exposed to nicotine-containing e-cigarette vapor exhibited significantly diminished lung growth and alveolar cell proliferation. In another study, bronchoalveolar lavage fluid samples were compared between non-exposed mice and mice exposed to e-cigarette vapor for $3 \mathrm{~d}$. The authors reported significantly greater levels of key proinflammatory markers (MCP-1, IL-6, IL-8) in bronchoalveolar lavage fluid collected from exposed mice versus non-exposed mice. ${ }^{20}$

Pre-clinical studies from human lung epithelial cells have revealed that exposure to e-cigarette vapor can lead to cytotoxicity, ${ }^{49-51}$ pro-inflammatory cytokine release, ${ }^{20,49}$ cellular morphology, ${ }^{49}$ and oxidative stress. ${ }^{51}$ These effects, while significant, were shown to be smaller in magnitude than effects due to cigarette smoke exposure. ${ }^{49,51} \mathrm{In}$ contrast, a study by Misra et $\mathrm{al}^{52}$ did not observe significant exposure effects related to cytotoxicity, mutagenicity, genotoxicity, or cytokine release.

A handful of clinical studies have investigated the effects of e-cigarette vapor exposure on pulmonary outcomes, 
typically comparing the effects to combustible cigarette smoking. Flouris et al ${ }^{53}$ examined the acute effects of ecigarettes versus combustible cigarettes on repeated measures of $\mathrm{FEV}_{1} / \mathrm{FVC}$ ratios. Fifteen combustible cigarette smokers underwent an active smoking session, a control session, and an active e-cigarette vaping session (all $30 \mathrm{~min}$ long). The smokers were compared to 15 never-smokers who were exposed to a passive, second-hand tobacco cigarette smoking session, a control session, and a passive e-cigarette vaping session (all $60 \mathrm{~min}$ long). $\mathrm{FEV}_{1} / \mathrm{FVC}$ decreased significantly due to active ( $\sim 7 \%$ decrease) shortterm exposure to cigarette smoking, but the results were not significant for passive exposure ( $\sim 3 \%$ decrease). While a downward trend was also observed for e-cigarettes, neither passive nor active exposure to vaping significantly compromised lung function.

In contrast, another study ${ }^{54}$ demonstrated that $5 \mathrm{~min}$ of vaping (nicotine dose of $11 \mathrm{mg} / \mathrm{mL}$ ) was sufficient to induce a statistically significant increase (18\%) in respiratory flow resistance and decrease (16\%) in expired nitric oxide. These effects resembled those brought about by smoking combustible cigarettes. Ferrari et al ${ }^{55}$ performed a similar experiment, but with nicotine-free e-cigarettes. In that study, vaping led to an appreciably smaller decline in forced expiratory flow at $25 \%$ of the pulmonary volume and $\mathrm{FEV}_{1}$ measures (relative to cigarette smoking). The decline was nonetheless statistically significant, suggesting a minor, but nontrivial, acute effect on airway constriction.

In a study of 25 smokers, Marini et al ${ }^{56}$ investigated the acute effects of vaping versus smoking with respect to changes in exhaled nitric oxide. The participants underwent 4 smoking/vaping sessions, in order: (1) a control session in which they vaped without the e-cigarette cartridge for $5 \mathrm{~min}$, (2) a combustible cigarette smoking session with their usual brand, (3) a nicotine-free e-cigarette vaping session for $5 \mathrm{~min}$, (4) and a nicotinecontaining $(18 \mathrm{mg} / \mathrm{mL})$ e-cigarette vaping session for $5 \mathrm{~min}$. Vapor analysis determined that vaping sessions, whether with nicotine-free or nicotine-containing e-cigarettes, induced immediate reductions in exhaled nitric oxide similar to those attributed to combustible cigarette smoking.

These clinical studies of e-cigarette vapor exposure on pulmonary outcomes vary in methodological features, such as type of e-cigarette, exposure session duration, and the measures of lung function. While such methodological and outcome differences make comparisons across the studies and integration of findings difficult, the results suggest that the impact of e-cigarette aerosol on the pulmonary system is not benign, and further research is needed, especially regarding long-term effects.

\section{Immune System}

Components of cigarette smoke, including nicotine, have been linked to impaired human immunity, affecting both immuno-suppressive and immuno-activating functions, and elevated risk of pulmonary infections and autoimmune diseases. Nicotine has been shown to suppress immune response, diminish antimicrobial defenses, and increase inflammation in in vitro studies. ${ }^{57,58}$ As such, the immunological effects of e-cigarettes raise concerns.

Hwang et a ${ }^{50}$ demonstrated that human lung alveolar type II epithelial cells treated with e-cigarette vapor had greater cell death compared to air-exposed cells. In addition, antimicrobial activity was diminished in human MRSA-infected keratinocytes after $1 \mathrm{~h}$ of exposure to e-cigarette vapor. Similarly, murine alveolar macrophages and human neutrophils, key mediators of innate immunity and bacterial clearance, showed attenuated antimicrobial activity after $2 \mathrm{~h}$ of exposure to e-cigarette vapor. These reductions in antimicrobial activity were independent of nicotine dose. Mouse inhalation of e-cigarette vapor for $1 \mathrm{~h} / \mathrm{d}$ for 4 weeks resulted in significant increases in inflammatory markers. Moreover, MRSA exposed to e-cigarette vapor demonstrated increased biofilm production and hydrophobicity, consistent with increased adherence to human keratinocytes relative to non-exposed MRSA.

Using a mouse model, Sussan et al ${ }^{59}$ demonstrated that e-cigarette vapor resulted in airway inflammation and impaired immune response to bacteria and viruses, including defective bacterial phagocytosis. Relative to lungs of air-exposed mice, lungs of e-cigarette vaporexposed mice contained significantly higher markers of oxidative stress. Vapor exposure triggered elevated macrophage levels in the airways that resembled those induced by cigarette smoke exposure, thereby suggesting a mild inflammatory airway response. Upon intranasal infection with Streptococcus pneumoniae, vaporexposed mice demonstrated an impaired antibacterial pulmonary response compared to controls. Similarly, mice infected intranasally with H1N1 influenza virus demonstrated elevated viral titers, weight loss, and death.

These initial pre-clinical studies suggest that e-cigarette vapor is harmful to airway cells, suppresses immune responses to bacteria and viruses, promotes inflammation, and may increase the virulence of bacteria. While more research is clearly necessary, the findings highlight the importance of evaluating potential risks of e-cigarette use for immunologically vulnerable populations, including surgical patients and those with cancer and HIV. 


\section{Effects of E-cigarettes on Smoking Cessation and Initiation}

\section{Smoking Cessation}

Smokers who have failed to quit smoking with evidence-based therapies ${ }^{9}$ may be more inclined to use the e-cigarette as a smoking cessation aid. Survey studies have shown that $67 \%$ of physicians believe e-cigarettes are useful smoking cessation aids, ${ }^{60}$ and $18 \%$ of smokers report that their providers recommended e-cigarettes for smoking cessation. ${ }^{61}$ While various studies have informed the debate on the efficacy of e-cigarettes for smoking cessation, ${ }^{62-64}$ only 2 randomized clinical trials ${ }^{65,66}$ have examined the effect of e-cigarettes on smoking cessation, and a third smaller trial ${ }^{67}$ evaluated the effect of e-cigarettes on smoking reduction. The results of these 2 clinical trials indicate that the efficacy of e-cigarettes for smoking cessation remains to be established, and it would be premature to broadly recommend e-cigarettes to those looking to quit smoking, given the unclear and potential chemical/toxin risks.

One clinical trial randomized 300 smokers without any intention to quit smoking to 1 of 3 e-cigarette conditions: $7.2 \mathrm{mg} / \mathrm{mL}$ nicotine for 12 weeks, $7.2 \mathrm{mg} / \mathrm{mL}$ nicotine for 6 weeks followed by $5.4 \mathrm{mg} / \mathrm{mL}$ for 6 weeks, or no nicotine for 12 weeks. ${ }^{68}$ Outcomes included smoking reduction and smoking abstinence. Given that none of the participants intended to quit, there were no significant differences between e-cigarette conditions. Across conditions, $10.3 \%$ of participants reported smoking reduction and $8.7 \%$ reported smoking abstinence at week 52. A second randomized clinical trial compared the effectiveness of e-cigarettes to that of transdermal nicotine for smoking cessation. ${ }^{66}$ Smokers who were motivated to quit were randomized to a nicotine-containing e-cigarette $(16 \mathrm{mg} / \mathrm{mL}$, $n=289)$, a nicotine patch $(n=295)$, or a placebo e-cigarette $(n=73)$. Levels of smoking abstinence at the 6-month follow-up were low, and there were no significant differences in smoking abstinence between the group that received the nicotine-containing e-cigarette and the group that received the nicotine patch $(7.3 \%$ with nicotine e-cigarette, $5.8 \%$ with patches, $4.1 \%$ with placebo e-cigarettes). The premise of these studies is that the e-cigarette, with its ability to deliver nicotine, can potentially serve as a smoking cessation aid. Various properties of the e-cigarette, in addition to the way it is used by the smoker, can alter nicotine yield. ${ }^{39} \mathrm{~A}$ strong evaluation of e-cigarettes as a cessation tool will require standardization of device, liquid, and training on how to use. Future research efforts investigating the clinical benefits of e-cigarettes must consider the regulatory implications of e-cigarettes as a cessation medication, as well as potential harms associated with use.
It has been suggested that e-cigarettes may facilitate reduction of cigarette use, offering an alternative to total abstinence while helping avoid exposure to combustionrelated toxicants and carcinogens. ${ }^{69}$ Adriaens et al ${ }^{67}$ evaluated cigarette intake in 48 smokers randomized to receive either 1 of 2 e-cigarette devices (both $18 \mathrm{mg} / \mathrm{mL}$ e-liquid) varying in voltage and resistance or no e-cigarette. After 8 weeks, one third of the smokers who received an e-cigarette reported smoking reduction, compared to none of the control group. Logically, it would seem that reduced cigarette consumption would be associated with reduced harm. However, a safe level of smoking has not been identified, ${ }^{70-72}$ and the health effects associated with the dual use of e-cigarettes and combustible cigarettes remain to be evaluated.

\section{Smoking Uptake}

Regardless of potential health risks or benefits for smoking cessation, e-cigarettes contain nicotine. Nicotine is harmful to the developing adolescent brain, ${ }^{42,73}$ and since 2011, there has been an 8-fold increase in adolescent ecigarette use. ${ }^{4}$ The availability of flavors is the most important reason given by adolescents for using e-cigarettes. ${ }^{10}$ While $27-37 \%$ of adolescents who never smoked combustible cigarettes report using flavored e-liquid with nicotine, $18-34 \%$ of adolescents are unsure as to whether their flavored e-liquid contains nicotine. ${ }^{74,75}$ These studies indicate that some adolescents may be unintentionally exposing themselves to nicotine.

A growing body of evidence supports initial findings that e-cigarettes are a catalyst for combustible cigarette smoking for adolescents who may not have otherwise smoked. ${ }^{12,76-78}$ Adolescents who had used e-cigarettes (but not combustible cigarettes) were 2.7 times more likely than adolescents who had never used e-cigarettes to initiate the use of combustible cigarettes 12 months later. ${ }^{12}$ Adolescents who used e-cigarettes more frequently had 2 times greater odds of exhibiting frequent and heavy smoking patterns at their 6-month follow-up. ${ }^{79}$ This association was stronger among adolescents who were nonsmokers at baseline. Emerging data suggest that e-cigarette use may also be associated with an increased risk of using other combustible tobacco products ${ }^{12}$ and traditional drugs of abuse..$^{80}$

\section{Summary}

E-cigarette devices have evolved to be more powerful and to more efficiently deliver nicotine. E-cigarette users are increasingly likely to use rechargeable e-cigarettes with higher voltage batteries and adjustable resistance, ${ }^{81}$ and higher nicotine delivery may increase the health risks associated with e-cigarette use. It will be important to mon- 


\section{Physiological Impact of E-Cigarettes}

itor the quantity of the chemical constituents in e-cigarette vapor, as well as their associated health consequences, in smokers and nonsmokers, over the long term. Overall, the current data do not support the efficacy of e-cigarettes for smoking cessation. Future research of e-cigarettes as a cessation tool will require standardization of product (eg, device, liquid, nicotine) and training in use (eg, how and when to use). Any putative benefit for smoking cessation must be weighed against short-and long-term health consequences of e-cigarette use itself. Effective interventions to prevent adolescent e-cigarette use are necessary given the risks for nicotine exposure and subsequent development of dependence, as well as the other risks of combustible cigarette smoking.

\section{REFERENCES}

1. Hon L, Inventor; Hon L, assignee. Flameless electronic atomizing cigarette. US patent 20060196518 A1. Sep 7, 2006.

2. Marynak KL, Gammon DG, King BA, et al. National and state trends in sales of cigarettes and e-cigarettes, U.S., 2011-2015. Am J Prev Med 2017;53(1):96-101.

3. Kasza KA, Ambrose BK, Conway KP, et al. Tobacco-product use by adults and youths in the United States in 2013 and 2014. N Engl J Med 2017;376(4):342-353.

4. Jamal A, Gentzke A, Hu SS, et al. Tobacco use among middle and high school students: United States, 2011-2016. MMWR Morb Mortal Wkly Rep 2017(65):361-367.

5. Etter JF, Bullen C. Electronic cigarette: users profile, utilization, satisfaction and perceived efficacy. Addiction 2011;106(11):2017-2028.

6. Choi K, Forster JL. Beliefs and experimentation with electronic cigarettes: a prospective analysis among young adults. Am J Prev Med 2014;46(2):175-178.

7. Huang J, Kornfield R, Emery SL. 100 Million views of electronic cigarette YouTube Videos and counting: quantification, content evaluation, and engagement levels of videos. J Med Internet Res 2016; 18(3):e67.

8. McRobbie H, Phillips A, Goniewicz ML, et al. Effects of switching to electronic cigarettes with and without concurrent smoking on exposure to nicotine, carbon monoxide, and acrolein. Cancer Prev Res (Phila) 2015;8(9):873-878.

9. Ray R, Schnoll RA, Lerman C. Nicotine dependence: biology, behavior, and treatment. Annu Rev Med 2009;60:247-260.

10. Ambrose BK, Day HR, Rostron B, et al. Flavored tobacco product use among US youth aged 12-17 years, 2013-2014. JAMA 2015; 314(17):1871-1873.

11. McMillen RC, Gottlieb MA, Shaefer RM, Winickoff JP, Klein JD. Trends in electronic cigarette use among U.S. adults: use is increasing in both smokers and nonsmokers. Nicotine Tob Res 2015;17(10): 1195-1202.

12. Leventhal AM, Strong DR, Kirkpatrick MG, et al. Association of electronic cigarette use with initiation of combustible tobacco product smoking in early adolescence. JAMA 2015;314(7):700-707.

13. Brownson EG, Thompson CM, Goldsberry S, et al. Explosion injuries from e-cigarettes. N Engl J Med 2016;375(14):1400-1402.

14. McKenna LA Jr. Electronic cigarette fires and explosions in the United States 2009-2016. Emmitsburg, MD: US Fire Administration; 2017. Available at: https://www.hsdl.org/?view\&did=804891. Accessed September 14, 2018.

15. Toxicology Data Network [database online]. Propylene glycol. CASRN: 57-55-6. Bethesda, MD: US National Library of Medicine; 2017. Available at: https://toxnet.nlm.nih.gov. Accessed May 4, 2017.
16. Laino T, Tuma C, Moor P, Martin E, Stolz S, Curioni A. Mechanisms of propylene glycol and triacetin pyrolysis. J Phys Chem A 2012;116(18):4602-4609.

17. Toxicology Data Network [database online]. 1,2-Propylene oxide. CASRN: 75-56-9. Bethesda, MD: US National Library of Medicine; 2017. Available at: https://toxnet.nlm.nih.gov/. Accessed April 20, 2017.

18. Toxicology Data Network [database online]. Glycerin: CASRN 5681-5. Bethesda, MD: US National Library of Medicine; 2017. Available at: https://toxnet.nlm.nih.gov/. Accessed April 20, 2017.

19. Toxicology Data Network [database online]. Acrolein. CASRN: 10702-8. Betheda, MD: US National Library of Medicine; 2017. Available at: https://toxnet.nlm.nih.gov/. Accessed April 20, 2017.

20. Lerner CA, Sundar IK, Yao H, et al. Vapors produced by electronic cigarettes and e-juices with flavorings induce toxicity, oxidative stress, and inflammatory response in lung epithelial cells and in mouse lung. PLoS One 2015;10(2):e0116732.

21. Brieger K, Schiavone S, Miller FJ Jr, Krause KH. Reactive oxygen species: from health to disease. Swiss Med Wkly 2012;142:w13659.

22. Etter JF. Throat hit in users of the electronic cigarette: an exploratory study. Psychol Addict Behav 2016;30(1):93-100.

23. Varlet V, Farsalinos K, Augsburger M, Thomas A, Etter JF. Toxicity assessment of refill liquids for electronic cigarettes. Int $\mathbf{J}$ Environ Res Public Health 2015;12(5):4796-4815.

24. Valentine GW, Jatlow PI, Coffman M, Nadim H, Gueorguieva R, Sofuoglu M. The effects of alcohol-containing e-cigarettes on young adult smokers. Drug Alcohol Depend 2016;159:272-276.

25. Cheng T. Chemical evaluation of electronic cigarettes. Tob Control. 2014;23(Suppl 2):ii11-ii17.

26. United States Environmental Protection Agency. Volatile organic compounds' impact on indoor air quality. Available at: https:// www.epa.gov/indoor-air-quality-iaq/volatile-organic-compoundsimpact-indoor-air-quality. Accessed July 3, 2017.

27. Agency for Toxic Substances and Disease Registry. Toxicological Profile for Polycyclic Aromatic Hydrocarbons. Atlanta: U.S. Department of Health and Human Services; 1995.

28. Goniewicz ML, Knysak J, Gawron M, et al. Levels of selected carcinogens and toxicants in vapour from electronic cigarettes. Tob Control 2014;23(2):133-139.

29. Williams M, Bozhilov K, Ghai S, Talbot P. Elements including metals in the atomizer and aerosol of disposable electronic cigarettes and electronic hookahs. PLoS One 2017;12(4):e0175430.

30. Fernandez E, Ballbe M, Sureda X, Fu M, Salto E, Martinez-Sanchez JM. Particulate matter from electronic cigarettes and conventional cigarettes: a systematic review and observational study. Curr Environ Health Rep 2015;2(4):423-429.

31. Lee MS, LeBouf RF, Son YS, Koutrakis P, Christiani DC. Nicotine, aerosol particles, carbonyls and volatile organic compounds in tobaccoand menthol-flavored e-cigarettes. Environ Health 2017;16(1):42.

32. Schripp T, Markewitz D, Uhde E, Salthammer T. Does e-cigarette consumption cause passive vaping? Indoor Air 2013;23(1):25-31.

33. McAuley TR, Hopke PK, Zhao J, Babaian S. Comparison of the effects of e-cigarette vapor and cigarette smoke on indoor air quality. Inhal Toxicol 2012;24(12):850-857.

34. Schober W, Szendrei K, Matzen W, et al. Use of electronic cigarettes (e-cigarettes) impairs indoor air quality and increases FeNO levels of e-cigarette consumers. Int J Hyg Environ Health 2014;217(6):628637.

35. National Institute for Occupational Safety and Health. FlavoringsRelated Lung Disease. Available at: https://www.cdc.gov/niosh/ topics/flavorings/exposure.html. Accessed July 1, 2017.

36. Barrington-Trimis JL, Samet JM, McConnell R. Flavorings in electronic cigarettes: an unrecognized respiratory health hazard? JAMA 2014;312(23):2493-2494. 


\section{Physiological Impact of E-Cigarettes}

37. Gerloff J, Sundar IK, Freter R, et al. Inflammatory response and barrier dysfunction by different e-cigarette flavoring chemicals identified by gas chromatography-mass spectrometry in e-liquids and e-vapors on human lung epithelial cells and fibroblasts. Appl In Vitro Toxicol 2017;3(1):28-40.

38. Goniewicz ML, Kuma T, Gawron M, Knysak J, Kosmider L. Nicotine levels in electronic cigarettes. Nicotine Tob Res 2013;15(1): 158-166.

39. Talih S, Balhas Z, Eissenberg T, et al. Effects of user puff topography, device voltage, and liquid nicotine concentration on electronic cigarette nicotine yield: measurements and model predictions. Nicotine Tob Res 2015;17(2):150-157.

40. Ramoa CP, Hiler MM, Spindle TR, et al. Electronic cigarette nicotine delivery can exceed that of combustible cigarettes: a preliminary report. Tob Control 2016;25(e1):e6-e9.

41. Farsalinos KE, Spyrou A, Tsimopoulou K, Stefopoulos C, Romagna G, Voudris V. Nicotine absorption from electronic cigarette use: comparison between first and new-generation devices. Sci Rep 2014; 4:4133.

42. Dwyer JB, McQuown SC, Leslie FM. The dynamic effects of nicotine on the developing brain. Pharmacol Ther 2009;122(2):125-139.

43. Farsalinos KE, Romagna G, Allifranchini E, et al. Comparison of the cytotoxic potential of cigarette smoke and electronic cigarette vapour extract on cultured myocardial cells. Int J Environ Res Public Health 2013;10(10):5146-5162.

44. Palpant NJ, Hofsteen P, Pabon L, Reinecke H, Murry CE. Cardiac development in zebrafish and human embryonic stem cells is inhibited by exposure to tobacco cigarettes and e-cigarettes. PLoS One 2015;10(5):e0126259.

45. Farsalinos KE, Tsiapras D, Kyrzopoulos S, Savvopoulou M, Voudris V. Acute effects of using an electronic nicotine-delivery device (electronic cigarette) on myocardial function: comparison with the effects of regular cigarettes. BMC Cardiovasc Disord 2014;14:78.

46. Antoniewicz L, Bosson JA, Kuhl J, et al. Electronic cigarettes increase endothelial progenitor cells in the blood of healthy volunteers. Atherosclerosis 2016;255:179-185.

47. Carnevale R, Sciarretta S, Violi F, et al. Acute impact of tobacco vs electronic cigarette smoking on oxidative stress and vascular function. Chest 2016;150(3):606-612.

48. McGrath-Morrow SA, Hayashi M, Aherrera A, et al. The effects of electronic cigarette emissions on systemic cotinine levels, weight and postnatal lung growth in neonatal mice. PLoS One. 2015;10(2): e0118344.

49. Cervellati F, Muresan XM, Sticozzi C, et al. Comparative effects between electronic and cigarette smoke in human keratinocytes and epithelial lung cells. Toxicol In Vitro 2014;28(5):999-1005.

50. Hwang JH, Lyes M, Sladewski K, et al. Electronic cigarette inhalation alters innate immunity and airway cytokines while increasing the virulence of colonizing bacteria. J Mol Med (Berl) 2016;94(6): 667-679.

51. Scheffler S, Dieken H, Krischenowski O, Forster C, Branscheid D, Aufderheide M. Evaluation of e-cigarette liquid vapor and mainstream cigarette smoke after direct exposure of primary human bronchial epithelial cells. Int J Environ Res Public Health 2015;12(4): 3915-3925.

52. Misra M, Leverette RD, Cooper BT, Bennett MB, Brown SE. Comparative in vitro toxicity profile of electronic and tobacco cigarettes, smokeless tobacco and nicotine replacement therapy products: e-liquids, extracts and collected aerosols. Int J Environ Res Public Health 2014;11(11):11325-11347.

53. Flouris AD, Chorti MS, Poulianiti KP, et al. Acute impact of active and passive electronic cigarette smoking on serum cotinine and lung function. Inhal Toxicol 2013;25(2):91-101.
54. Vardavas CI, Anagnostopoulos N, Kougias M, Evangelopoulou V, Connolly GN, Behrakis PK. Short-term pulmonary effects of using an electronic cigarette: impact on respiratory flow resistance, impedance, and exhaled nitric oxide. Chest 2012;141(6): 1400-1406

55. Ferrari M, Zanasi A, Nardi E, et al. Short-term effects of a nicotinefree e-cigarette compared to a traditional cigarette in smokers and non-smokers. BMC Pulm Med 2015;15:120.

56. Marini S, Buonanno G, Stabile L, Ficco G. Short-term effects of electronic and tobacco cigarettes on exhaled nitric oxide. Toxicol Appl Pharmacol 2014;278(1):9-15.

57. Mahapatra SK, Bhattacharjee S, Chakraborty SP, Majumdar S, Roy $\mathrm{S}$. Alteration of immune functions and Th1/Th2 cytokine balance in nicotine-induced murine macrophages: immunomodulatory role of eugenol and $\mathrm{N}$-acetylcysteine. Int Immunopharmacol 2011;11(4): 485-495.

58. Matsunaga K, Klein TW, Friedman H, Yamamoto Y. Involvement of nicotinic acetylcholine receptors in suppression of antimicrobial activity and cytokine responses of alveolar macrophages to Legionella pneumophila infection by nicotine. J Immunol 2001; 167(11):6518.

59. Sussan TE, Gajghate S, Thimmulappa RK, et al. Exposure to electronic cigarettes impairs pulmonary anti-bacterial and anti-viral defenses in a mouse model. PLoS One. 2015;10(2):e0116861.

60. Kandra KL, Ranney LM, Lee JG, Goldstein AO. Physicians' attitudes and use of e-cigarettes as cessation devices, North Carolina, 2013. PLoS One 2014;9(7):e103462.

61. Berg CJ, Haardoerfer R, Escoffery C, Zheng P, Kegler M. Cigarette users' interest in using or switching to electronic nicotine delivery systems for smokeless tobacco for harm reduction, cessation, or novelty: a cross-sectional survey of US adults. Nicotine Tob Res 2015; 17(2):245-255.

62. Brown J, Beard E, Kotz D, Michie S, West R. Real-world effectiveness of e-cigarettes when used to aid smoking cessation: a crosssectional population study. Addiction 2014;109(9):1531-1540.

63. Siegel MB, Tanwar KL, Wood KS. Electronic cigarettes as a smoking-cessation: tool results from an online survey. Am J Prev Med 2011;40(4):472-475.

64. Rahman MA, Hann N, Wilson A, Mnatzaganian G, Worrall-Carter L. E-cigarettes and smoking cessation: evidence from a systematic review and meta-analysis. PLoS One 2015;10(3):e0122544.

65. Caponnetto P, Cibella F, Mancuso S, Campagna D, Arcidiacono G, Polosa R. Effect of a nicotine free inhalator as part of a smoking cessation program. Eur Respir J. 2011;38.

66. Bullen C, Howe C, Laugesen M, et al. Electronic cigarettes for smoking cessation: a randomised controlled trial. Lancet 2013; 382(9905):1629-1637.

67. Adriaens K, Van Gucht D, Declerck P, Baeyens F. Effectiveness of the electronic cigarette: an eight-week Flemish study with six-month follow-up on smoking reduction, craving and experienced benefits and complaints. Int J Environ Res Public Health 2014;11(11):1122011248.

68. Caponnetto P, Campagna D, Cibella F, et al. Efficiency and safety of an electronic cigarette (ECLAT) as tobacco cigarettes substitute: a prospective 12-month randomized control design study. PLoS One 2013;8(6):e66317.

69. Hajek P. Electronic cigarettes have a potential for huge public health benefit. BMC Med 2014;12:225.

70. Bjartveit K, Tverdal A. Health consequences of smoking 1-4 cigarettes per day. Tob Control 2005;14(5):315-320.

71. Tverdal A, Bjartveit K. Health consequences of reduced daily cigarette consumption. Tob Control 2006;15(6):472-480.

72. Godtfredsen NS, Holst C, Prescott E, Vestbo J, Osler M. Smoking reduction, smoking cessation, and mortality: a 16-year follow-up of 


\section{Physiological Impact of E-Cigarettes}

19,732 men and women from the Copenhagen Centre for Prospective Population Studies. Am J Epidemiol 2002;156(11):994-1001.

73. England LJ, Bunnell RE, Pechacek TF, Tong VT, McAfee TA. Nicotine and the developing human: a neglected element in the electronic cigarette debate. Am J Prev Med 2015;49(2):286-293.

74. Krishnan-Sarin S, Morean ME, Camenga DR, Cavallo DA, Kong G. E-cigarette use among high school and middle school adolescents in Connecticut. Nicotine Tob Res 2015;17(7):810-818.

75. Morean ME, Kong G, Cavallo DA, Camenga DR, Krishnan-Sarin S. Nicotine concentration of e-cigarettes used by adolescents. Drug Alcohol Depend 2016;167:224-227.

76. Primack BA, Soneji S, Stoolmiller M, Fine MJ, Sargent JD. Progression to traditional cigarette smoking after electronic cigarette use among us adolescents and young adults. JAMA Pediatr 2015;169(11):1018-1023.

77. Wills TA, Sargent JD, Gibbons FX, Pagano I, Schweitzer R. E-cigarette use is differentially related to smoking onset among lower risk adolescents. Tob Control. 2016.
78. Soneji S, Barrington-Trimis JL, Wills TA, et al. Association between initial use of e-cigarettes and subsequent cigarette smoking among adolescents and young adults: a systematic review and meta-analysis. JAMA Pediatr. 2017;171(8):788-797.

79. Leventhal AM, Stone MD, Andrabi N, et al. Association of e-cigarette vaping and progression to heavier patterns of cigarette smoking. JAMA 2016;316(18):1918-1920.

80. Miech RA, O'Malley PM, Johnston LD, Patrick ME. E-cigarettes and the drug use patterns of adolescents. Nicotine Tob Res 2016; 18(5):654-659.

81. Chen C, Zhuang YL, Zhu SH. E-cigarette design preference and smoking cessation: a U.S. population study. Am J Prev Med 2016; 51(3):356-363

82. Centers for Disease Controls. Electronic cigarettes: what's the bottom line? Available at: https://upload.wikimedia.org/wikipedia/commons/6/61/ Electronic_Cigarettes\%2C_What_is_the_bottom_line_CDC.pdf. Accessed July 1, 2018. 